07

\title{
Преобразование полупроводниковых наночастиц в плазмонные материалы путем направленной замены органических лигандов, связанных с их поверхностью
}

\author{
(С) П.С. Самохвалов ${ }^{1}$, Д.О. Володин ${ }^{1}$, С.В. Бозрова ${ }^{1}$, Д.С. Довженко ${ }^{1}$, М.А. Звайгзне ${ }^{1}$, П.А. Линьков ${ }^{1}$, \\ Г.О. Нифонтова ${ }^{1}$, И.О. Петрова ${ }^{1}$, А.В. Суханова ${ }^{1,2}$, И.Р. Набиев ${ }^{1,2}$ \\ ${ }^{1}$ Национальный исследовательский ядерный университет „МИФИ“, Москва, Россия \\ 2 Лаборатория по исследованиям в области нанонаук, ЛРН-ЕА4682, \\ Университет г. Реймса, Шампань-Арденн, Реймс, Франция \\ E-mail: p.samokhvalov@gmail.com
}

Поступило в Редакцию 10 декабря 2018г

В окончательной редакции 27 декабря 2018 г.

Принято к публикации 27 декабря 2018г.

Плазмонные наночастицы стали признанным инструментом исследований в оптоэлектронике, фотонике и биомедицинских приложениях. Появившиеся относительно недавно полупроводниковые плазмонные наночастицы в отличие от металлических характеризуются плазмонными оптическими переходами в ИК-области и имеют отличные перспективы применения. В этой работе впервые показана возможность преобразования полупроводниковых (экситонных) флуоресцентных нанокристаллов — квантовых точек состава $\mathrm{CuInS} 2$ в плазмонные наночастицы путем постсинтетической обработки, без изменения химического состава неорганической части нанокристаллов.

DOI: 10.21883/PJTF.2019.07.47528.17631

Плазмонный резонанс возникает вследствие коллективных осцилляций электронов проводимости относительно их равновесных позиций, которые могут быть вызваны приходящей электромагнитной волной, электрический компонент которой вызывает возмущение свободных носителей. В настоящее время плазмонные наноструктуры и наночастицы находят применение в оптическом сенсинге, при использовании эффекта чувствительности положения максимума плазмонного резонанса к параметрам окружения [1]. Кроме того, такие наноструктуры проявляют эффект локального усиления электромагнитного поля, в результате чего становится возможным гигантское комбинационное рассеяние света [2]. К тому же указанные наноструктуры могут выступать в роли волноводов для передачи оптических сигналов в результате ближнепольных взаимодействий [3]. Одним из последних, наиболее „горячих“ направлений применения плазмонных наночастиц является эффект взаимодействия свет-вещество в режиме сильной связи [4], в котором плазмонные наночастицы выступают в роли источника сильно локализованного мощного электромагнитного поля. Кроме того, связывание флуоресцентных полупроводниковых нанокристаллов (НК) - экситонных квантовых точек (КТ), которые представляют собой один из наиболее развитых на текущий момент продуктов нанотехнологий [5], - и плазмонных наночастиц позволяет существенно увеличить световой выход КТ вследствие эффекта слабой связи и достичь как минимум пятикратного увеличения интенсивности сигнала флуоресценции [6].
В настоящей работе демонстрируется возможность превращения флуоресцентных экситонных КТ состава $\mathrm{CuInS}_{2}$ в полупроводниковые плазмонные наночастицы (ППНЧ) с плазмонным резонансным оптическим переходом в ближней ИК-области. При этом важно, что такое превращение осуществляется методом постсинтетической обработки наночастиц, без изменения их химической природы. Предложенный подход позволяет существенно упростить получение ППНЧ по унифицированной методике и избежать использования малостабильных и дорогих реагентов.

Коллоидный синтез КТ состава $\mathrm{CuInS}_{2}$ проводился при $230^{\circ} \mathrm{C}$ согласно опубликованной ранее методике [7] с использованием ацетата индия (III), иодида меди (I) и додекантиола в качестве исходных веществ. Постсинтетическая обработка полученных $\mathrm{KT} \mathrm{CuInS}_{2}$, заключающаяся в замене поверхностных органических лигандов (исходного додекантиола на олеиламин), проводилась следующим образом. К раствору КТ в толуоле добавляли $2.5 \mathrm{ml}$ олеиламина и $100 \mathrm{mg} \mathrm{NaBH}$, после чего смесь интенсивно перемешивали в течение $15 \mathrm{~min}$ и осаждали добавлением избытка метанола. Далее смесь центрифугировали, удаляли супернатант и повторяли процедуру обработки олеиламином в присутствии $\mathrm{NaBH}_{4}$. После повторной обработки и отделения КТ от избытка олеиламина путем осаждения и центрифугирования очищенные $\mathrm{KT} \mathrm{CuInS}_{2}$ с молекулами олеиламина на поверхности растворяли в толуоле и переносили в смесь $6 \mathrm{ml}$ 1-октадецена и $6 \mathrm{ml}$ олеиламина. Далее смесь вакуумировалась при умеренном нагреве до $100^{\circ} \mathrm{C}$, в результате чего по существенному изменению спект- 

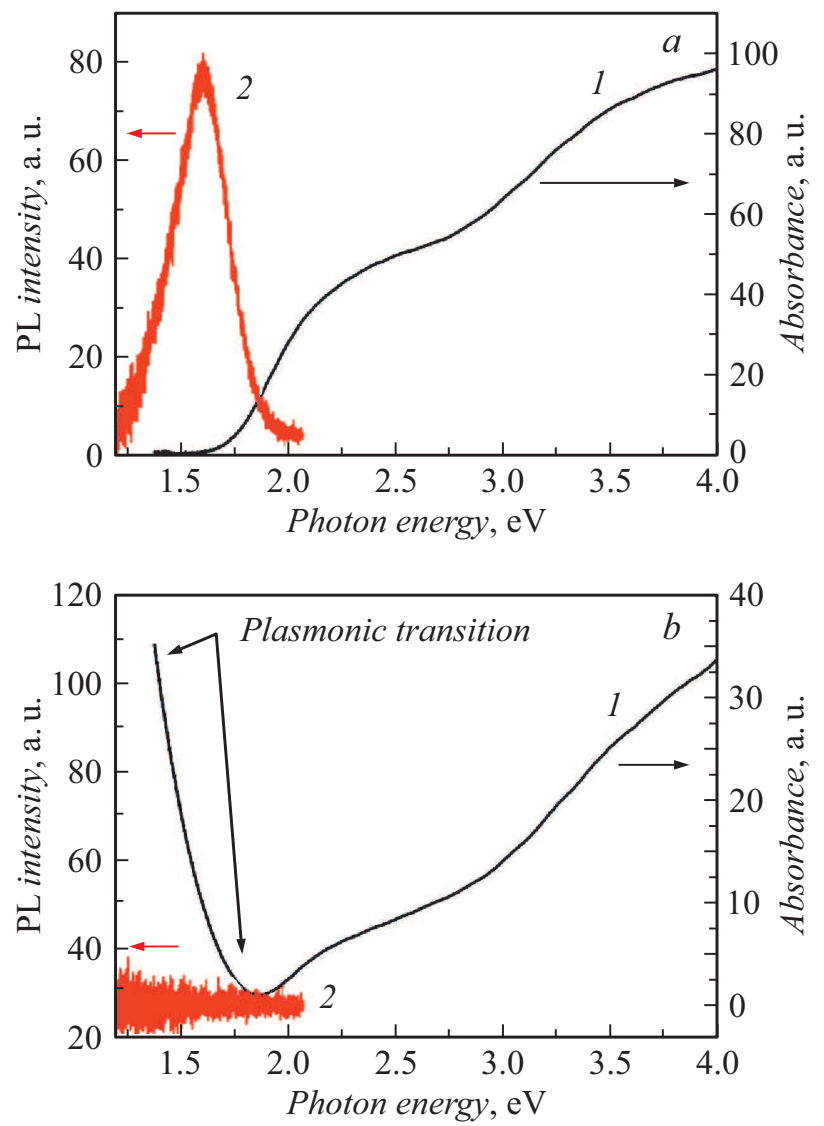

Рис. 1. Спектры поглощения (1) и флуоресценции (2) нанокристаллов $\mathrm{CuInS}_{2}$ до $(a)$ и после $(b)$ постсинтетической обработки.

ральных характеристик фиксировалось преобразование KT CuInS 2 в ППНЧ.

Предложенный в настоящей работе метод получения ППНЧ основан на процедуре обмена поверхностных лигандов, широко применяемой в синтезе КТ на основе селенида кадмия [8]. Однако, в отличие от аналогичной процедуры в случае KT CdSe, обмен лигандов KT $\mathrm{CuInS}_{2}$ с последующим удалением промежуточного растворителя - толуола - посредством вакуумирования раствора при нагреве до $100^{\circ} \mathrm{C}$ привел к преобразованию КТ $\mathrm{CuInS}_{2}$ в плазмонные НК того же состава. Об этом свидетельствуют полное пропадание сигнала флуоресценции в ближней ИК-области и появление интенсивной полосы в области $<1.8 \mathrm{eV}$ в спектре поглощения образца, отобранного из раствора после завершения дегазации (рис. 1, $b$, спектрофотометр Agilent Cary 60, длина оптического пути $10 \mathrm{~mm}$, гексан в качестве растворителя). Интерпретировать такое изменение спектров флуоресценции и поглощения $\mathrm{HK} \mathrm{CuInS}_{2}$ как переход экситонных наночастиц в плазмонные позволяют данные работ, посвященных синтезу и исследованию свойств плазмонных наночастиц на основе тройных и двойных соединений ряда $\mathrm{Cu}-\mathrm{In}-\mathrm{S}(\mathrm{Se})[9,10]$.
Более детальный анализ плазмонного перехода в полученных ППНЧ можно провести, используя для регистрации спектров поглощения в ближней/средней ИК-области детектор на основе InGaAs (рис. 2, спектрофотометр Avantes AvaSpec-NIR256-1.7). Как видно из приведенного спектра (линия 2), максимум плазмонного перехода ППНЧ $\mathrm{CuInS}_{2}$ соответствует энергии $\sim 0.85 \mathrm{eV}$, что близко к энергии для описанных ранее систем [9]. С помощью выражения, описывающего зависимость плазмонной частоты от концентрации свободных носителей (в данном случае дырок) в упрощенной модели свободного электронного газа, можно найти последнюю величину для исследуемых ППНЧ:

$$
\omega_{p}=\sqrt{\frac{n e^{2}}{m_{h} \varepsilon_{0}}},
$$

где $\omega_{p}-$ плазмонная частота, которая исходя из спектрального положения плазмонного резонанса определена как $\sim 2.49 \mathrm{eV}$ с использованием подхода, приведенного в работе [11], $n$ - искомая концентрация носителей (дырок), $e-$ заряд электрона, $m_{h}$ - эффективная масса дырок для $\mathrm{CuInS}_{2}$, равная 1.3 массы электрона [12], $\varepsilon_{0}$ - диэлектрическая проницаемость вакуума. Решение уравнения (1) относительно $n$ позволило установить значение концентрации дырок в полученных ППНЧ: $n=5.9 \cdot 10^{21} \mathrm{~cm}^{-3}$. С учетом среднего диаметра НК $\sim 3.7 \mathrm{~nm}$ (объем $\sim 15 \mathrm{~nm}^{3}$ ), определенного исходя из приведенного на рис. 1, $a$ спектра поглощения исходных КТ с использованием данных работы [13], можно получить верхнюю оценку в 87 единиц для среднего количества дырочных носителей на одну ППНЧ. Эта величина близка по порядку к найденной в работе [11] для нанокристаллов $\mathrm{Cu}_{2-x} \mathrm{~S}$ и значительно превышает величину, приведенную в работе [9], которая, впрочем,

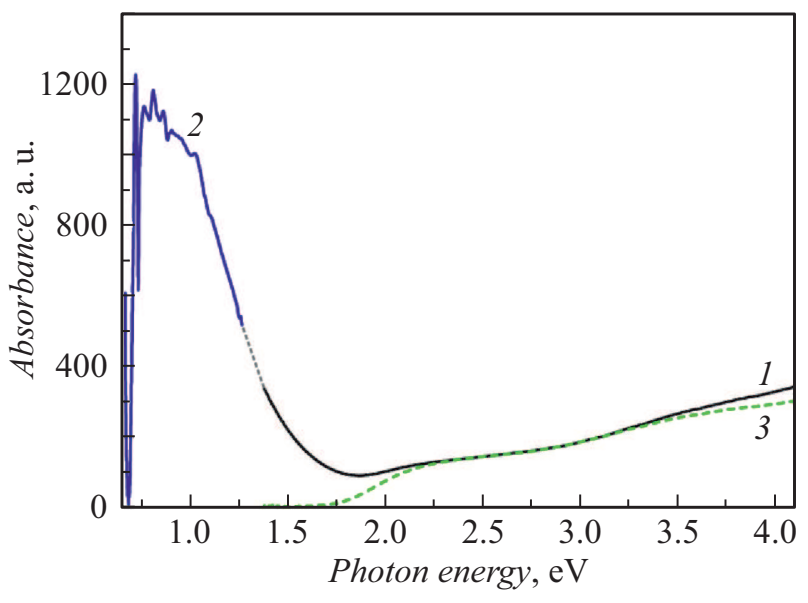

Рис. 2. Спектр поглощения полупроводниковых плазмонных наночастиц состава $\mathrm{CuInS}_{2} .1$ - спектр, зарегистрированный с использованием фотодиода в качестве детектора, 2 - спектр, зарегистрированный в ближней ИК-области с применением матричного детектора InGaAs, 3 - спектр KT $\mathrm{CuInS}_{2}$ до проведения постсинтетической обработки. 

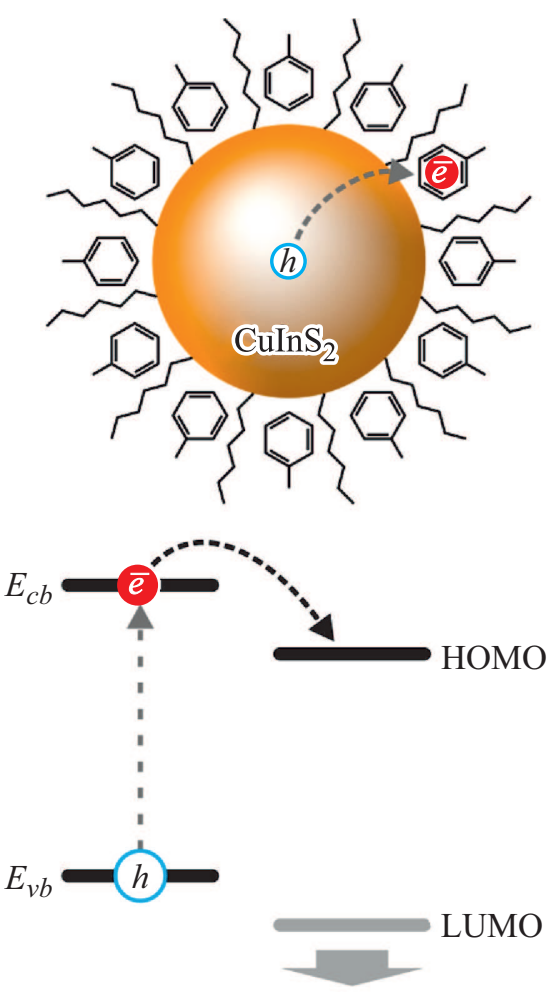

$\mathrm{CuInS}_{2}$

Toluene

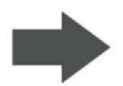

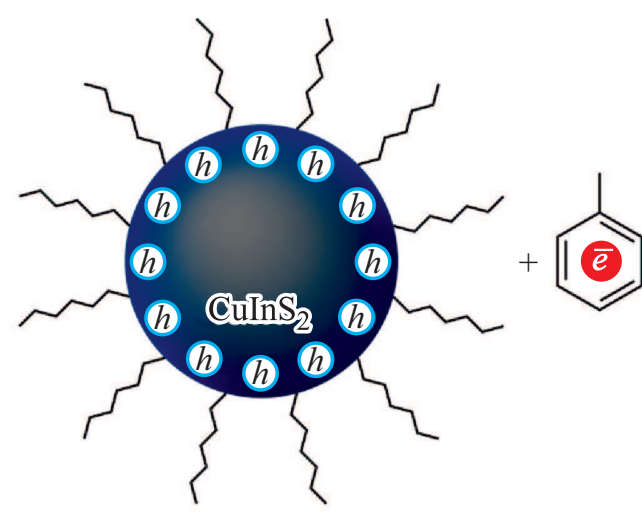
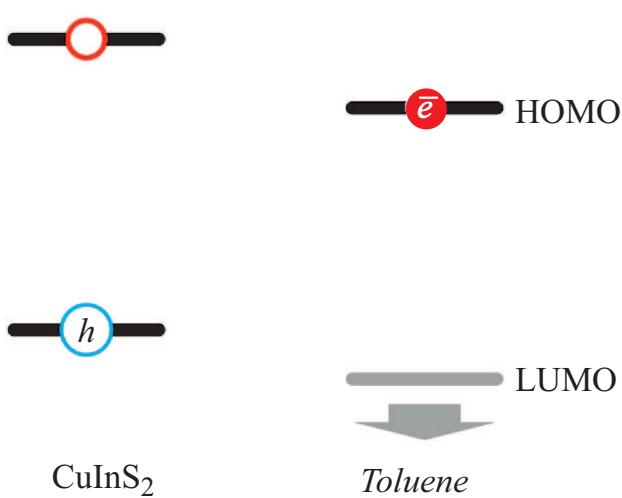

Toluene

Рис. 3. Энергетическая диаграмма системы квантовые точки $\mathrm{CuInS}_{2}$-толуол и возможный механизм превращения КТ в полупроводниковые плазмонные наночастицы.

определялась самими авторами как слишком низкая для столь интенсивно проявляющихся плазмонных свойств у полученных ими нанокристаллов $\mathrm{Cu}_{x} \mathrm{In}_{y} \mathrm{~S}_{2}$.

В качестве причины преобразования экситонных квантовых точек в плазмонные нанокристаллы можно рассмотреть две основные гипотезы. В ряде работ, например в [10], наличие плазмонного перехода в нестехиометрических НК состава $\mathrm{Cu}_{x} \operatorname{In}_{y} \mathrm{~S}_{2}$ связывается с присутствием вакансий в позициях ионов меди в кристаллической решетке. Процесс образования вакансий меди за счет удаления ионов из НК сопровождался бы сдвигом полосы поглощения в синюю область и сильным падением поглощения в УФ-области. Однако, как видно из сравнения спектров образцов НК $\mathrm{CuInSn}_{2}$ до и после обработки (рис. 2, линии 3 и 1 соответственно), в УФобласти наблюдается, напротив, повышение оптической плотности, а в видимой области форма спектра поглощения практически не изменяется. Следовательно, образование вакансий в кристаллической решетке НК не может служить единственной причиной наблюдаемого эффекта.

Альтернативная причина обнаруженного явления может заключаться в фотоиндуцированном переносе заряда [14] из нанокристаллов на акцептор электронов, которым в данном случае служит молекула промежуточного растворителя - толуола. На рис. 3 приведена энергетическая диаграмма системы КТ $\mathrm{CuInSn}_{2}-$ мо- лекула толуола. Положения энергетических уровней КТ приведены согласно данным работы [15]; для молекулы толуола положение высшей занятой молекулярной орбитали (НОМО) определено исходя из его потенциала ионизации, равного $8.82 \mathrm{eV}$, а значение энергии низшей свободной молекулярной орбитали (LUMO) рассчитано c учетом энергии первого молекулярного оптического перехода в спектре поглощения, равной $\sim 4.63 \mathrm{eV}$. Как видно из диаграммы, фотоиндуцированный перенос электрона из НК на молекулу толуола является энергетически выгодным, вследствие чего в ансамбле КТ состава $\mathrm{CuInS}_{2}$ можно ожидать образование стационарных комплексов с переносом зарядов. При вакуумировании часть молекул толуола удаляется из системы в заряженном состоянии (анион толуола является устойчивым благодаря делокализации заряда в $\pi$-системе), при этом остаются избыточные дырочные носители в $\mathrm{HK} \mathrm{CuInS}_{2}$. Роль предварительной замены лигандов заключается в „разрежении“ органической оболочки, служащей диэлектрической преградой для переноса зарядов и снижающей долю стационарных комплексов с переносом зарядов при обычных условиях.

Таким образом, в работе продемонстрирована возможность применения однотипного подхода для получения флуоресцентных или плазмонных наночастиц состава $\mathrm{CuInS}_{2}$ с флуоресценцией или плазмонным резонансным переходом в ближней ИК-области, не затрагивающими 
ни внутреннюю структуру, ни химический состав нанокристаллов. Полученные уникальные полупроводниковые НК, обладающие при этом плазмонными свойствами, могут найти широкое применение в ИК-спектроскопии, экологии и технологиях энергосбережения (для создания „умных“ окон), а также за счет своего малотоксичного химического состава в биомедицине в качестве ИК-меток или компонентов систем фотодинамической терапии.

Работа выполнена при поддержке Министерства науки и высшего образования РФ (соглашение 14.587.21.0039, ID RFMEFI58717X0039).

\section{Список литературы}

[1] Spackova B., Wrobel P., Bockova M., Homola J. // Proc. IEEE. 2016. V. 104. N 12. P. 2380-2408.

DOI: $10.1109 /$ JPROC.2016.2624340

[2] Fleischmann M., Hendra P.J., McQuillan A.J. // Chem. Phys. Lett. 1974. V. 26. N 2. P. 163-166.

DOI: $10.1016 / 0009-2614(74) 85388-1$

[3] Maier S.A., Kik P.G., Atwater H.A., Meltzer S., Harel E., Koel B.E., Requicha A.A.G. // Nature Mater. 2003. V. 2. N 4. P. 229-232. DOI: $10.1038 /$ nmat 852

[4] Dovzhenko D.S., Ryabchuk S.V., Rakovich Y.P., Nabiev I.R. // Nanoscale. 2018. V. 10. N 8. P. 3589-3605.

DOI: $10.1039 / \mathrm{C} 7 \mathrm{NR} 06917 \mathrm{~K}$

[5] Samokhvalov P., Artemyev M., Nabiev I. // Chemistry - A Eur. J. 2013. V. 19. N 5. P. 1534-1546.

DOI: $10.1002 /$ chem.201202860

[6] Kulakovich O., Strekal N., Yaroshevich A., Maskevich S., Gaponenko S., Nabiev I., Woggon U., Artemyev M. // Nano Lett. 2002. V. 2. N 12. P. 1449-1452. DOI: $10.1021 / \mathrm{nl} 025819 \mathrm{k}$

[7] Li L., Pandey A., Werder D.J., Khanal B.P., Pietryga J.M., Klimov V.I. // J. Am. Chem. 2011. V. 133. N 5. P. 1176-1179. DOI: $10.1021 / \mathrm{ja} 108261 \mathrm{~h}$

[8] Krivenkov V., Samokhvalov P., Zvaigzne M., Martynov I., Chistyakov A., Nabiev I. // J. Phys. Chem. C. 2018. V. 122. N 27. P. 15761-15771. DOI: 10.1021 acs.jpcc.8b04544

[9] Niezgoda J.S., Harrison M.A., McBride J.R., Rosenthal S.J. // Chem. Mater. 2012. V. 24. N 16. P. 3294-3298.

DOI: $10.1021 / \mathrm{cm} 3021462$

[10] Lesnyak V., Brescia R., Messina G.C., Manna L. // J. Am. Chem. Soc. 2015. V. 137. N 29. P. 9315-9323. DOI: $10.1021 /$ jacs.5b03868

[11] Luther J.M., Jain P.K., Ewers T., Alivisatos A.P. // Nature Mater. 2011. V. 10. N 5. P. 361-366. DOI: $10.1038 / \mathrm{nmat} 3004$

[12] Look D.C., Manthuruthil J.C. // J. Phys. Chem. Solids. 1976. V. 37. N 2. P. 173-180. DOI: 10.1016/0022-3697(76)90157-8

[13] Xia C., $W u \quad W ., \quad Y u \quad T$., Xie X., van Oversteeg C., Gerritsen H.C., de Mello Donega C. // ACS Nano. 2018. V. 12. N 8. P. 8350-8361. DOI: 10.1021/acsnano.8b03641

[14] Vokhmintcev K.V., Samokhvalov P.S., Nabiev I. // Nano Today. 2016. V. 11. N 2. P. 189-211.

DOI: 10.1016/j.nantod.2016.04.005

[15] Sun J., Zhao J., Masumoto Y. // Appl. Phys. Lett. 2013. V. 102. N 5. P. 053119 . DOI: $10.1063 / 1.4790603$ 